\title{
Autoshaping with several concurrently available conditioned stimuli
}

\author{
RICHARD PISACRETA, EDWARD REDWOOD, and KEVIN WITT \\ Ferris State College, Big Rapids, Michigan 49307
}

\begin{abstract}
Nine pigeons were trained with an autoshaping procedure that provided six concurrent conditioned stimuli (CSs). Each bird pecked particular keys within 2-133 trials (group mean = 49). The CSs included a white key, a flickering white key, an alternating white light with a white " $x$," and a white light that moved across three keys. Rearranging the CSs on the keys did not greatly influence the response distributions of seven of the birds.
\end{abstract}

The autoshaping procedure introduced by Brown and Jenkins (1968) is frequently used to train naive pigeons to peck response keys. An experimentally naive bird is taught to readily eat from a grain feeder. Trials consist of an 8-sec presentation of a white key light followed by $4 \mathrm{sec}$ access to grain. Each trial is separated by a variableinterval (VI) 60 -sec period. No response is required to yield a reinforcer. Procedurally, it is a classical conditioning paradigm in which the lighted key serves as the conditioned stimulus (CS) and the grain functions as the unconditioned stimulus (US). A keypeck cancels the remainder of the CS interval and produces the US. Although it is not required, pigeons typically peck the lighted key after a number of CS-US pairings. In the Brown and Jenkins study, the mean number of trials before the keypeck emerged was 45 (range $=6-119$ ).

Besides being a useful shaping technique, autoshaping has generated interest because it appears to blur the distinction between classical and operant conditioning. Hence, research has been directed toward providing explanatory mechanisms. Allaway (1971), Egger and Miller (1963), and Gamzu and Williams (1973) proposed that autoshaped keypecking depends on the informativeness of the CS. For example, Allaway (1971) presented a tone CS for $2 \sec$ followed by a 6 -sec presentation of tone plue key light. Hence, the key light was a redundant CS. Some birds failed to peck the key; others pecked infrequently. The results suggested that the informativeness of the key light and not the pairing of it with the US contributes to autoshaped behavior. Wasserman (1972) and Wasserman and Anderson (1974) provided similar results. Other explanatory mechanisms have included sign tracking (Hearst \& Jenkins, 1974), stimulus surrogation (Gamzu, 1971), superstition (Brown \& Jenkins, 1968), and the US as an incentive stimulus (Bindra, 1972). (For a comprehensive review, see Hearst \& Jenkins, 1974; Schwartz \& Gamzu, 1977.)

A special thanks to Lauraine Pisacreta for her skillful editing of the paper. Reprints may be obtained from R. Pisacreta, Department of Psychology, Ferris State College, Big Rapids, Michigan 49307.
Choice situations represent a sensitive behavioral measure with reinforcement schedules (e.g., Ferster \& Skinner, 1957). Employing choice procedures with classical conditioning has been infrequent (e.g., Fisher \& Catania, 1977). Is choice behavior sensitive with autoshaping procedures? A few studies suggest it is. Williams and Williams (1969) presented two concurrently available keys (CSs). Pecks to one key canceled the scheduled reinforcer. Pecks to the other key had no programmed consequence. The birds responded predominantly to the key that did not cancel grain. Similar data were provided by Schwartz and Williams (1972). Both Gonzales (1974) and Picker and Poling (1982) paired a particular CS with a different percentage of CS-US pairings. In the Picker and Poling (1982) study, three concurrently available CSs were presented: red, green, and a cross. Responses to the red, cross, or green CS produced grain $100 \%, 50 \%$, and $0 \%$ of the trials, respectively. The birds pecked the red and cross.

In many of these studies, the possibility exists that responding may be a matter of adventitious (superstitious) keypecks; that is, mere CS-US contiguity contributes to maintained responding. The present study tested that hypothesis by providing several different CSs with the same contingency. A peck to any CS produced grain immediately. After pecking emerged, the CSs were redistributed on the keys to ascertain if the birds were pecking particular stimuli or particular keys.

\section{METHOD}

\section{Subjects}

Nine naive White Carneaux pigeons, maintained at $80 \% \pm$ $15 \mathrm{~g}$ of their free-feeding weights, were employed.

\section{Apparatus}

The apparatus was a $35 \times 35 \times 37 \mathrm{~cm}$ operant conditioning chamber enclosed in a sound-attenuating hull. A $20 \times 25 \mathrm{~cm}$ piece of one-way glass mounted on the outer hull allowed observation of the experimental area.

The intelligence panel was $37 \times 35 \mathrm{~cm}$ and provided nine pecking keys. Each key was $2.7 \mathrm{~cm}$ in diameter (BRS/LVE Model 121-16), and the keys were arranged in a 3 by 3 matrix. For reference, the keys are numbered from upper left (1) 
across to lower right (9). IEE in-line projectors (Model 1813-44) rear-projected the stimuli onto each key. Only the upper six keys were used. Keys 7, 8, and 9 were never illuminated. The operating force requirement of each key was approximately $.16 \mathrm{~N}$. The horizontal and vertical distances between the keys were 8.1 and $6.4 \mathrm{~cm}$, respectively, center to center. A $6 \times 6 \mathrm{~cm}$ feeder aperture was centered on the wall $10 \mathrm{~cm}$ above the floor. The feeder (BRS/LVE Model 114-10) provided $3 \mathrm{sec}$ access to grain. The houselight, a GE Model 1820 lamp, continually directed light toward the ceiling. White noise and a fan masked extraneous noise. An E and L Instruments MMD-1 computer recorded data and controlled experimental events.

\section{Procedure}

Each bird was magazine trained until it approached and ate from the feeder within $2 \mathrm{sec}$ of its activation. Another 1003 -sec reinforcers were provided to each bird. Afterward, autoshaping training began. A trial presented six CSs followed $8 \mathrm{sec}$ later by $3 \mathrm{sec}$ access to grain. The intertrial interval was $30 \mathrm{sec}$. No response was ever required. Any keypeck immediately terminated the CSs and produced grain. Four different CS arrangements were used and are presented as Figure 1. For reference, the upper keys are (from left to right) Keys 1, 2, and 3; the lower keys are Keys 4, 5, and 6.

Autoshaping Condition 1 (AS1) shows that the following CSs were provided. Key 4 presented a stationary white field. Key 5 presented a white field that alternated with a white " $x$ " projected on a black background. The two stimuli alternated every $1.0 \mathrm{sec}$ of the 8 -sec CS interval. Key 6 presented a white light for .5 -sec intervals. The key was dark during the alternate .5 -sec intervals. The upper three keys are referred to as the moving condition. Key 1 presented white for $1.0 \mathrm{sec}$, and Keys 2 and 3 were dark. One second later, Keys 1 and 3 were dark and Key 2 presented white. During the 8-sec CS interval, the white light appears (to the human eye) to move across the keys in the sequence $1,2,3,2,1,2,3$, and 2 , followed by the grain delivery. Each session presented 50 CS-US pairings. Each bird was treated to sessions with AS1 until a keypeck emerged, and each bird responded on at least $50 \%$ of the trials. Each bird was then exposed to sessions with AS2, AS3, AS4, and, finally, AS1 again. The only difference between the four AS conditions was the spatial arrangement of the CSs.

\section{RESULTS}

Table 1 displays the trial of first keypeck occurrence produced by each bird under each AS condition. The

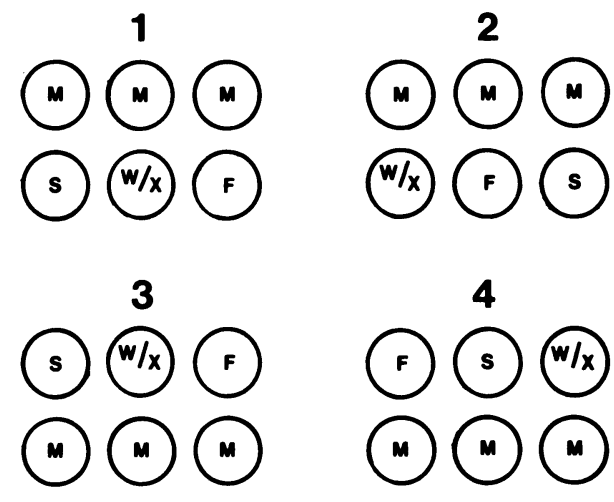

Figure 1. The various CS spatial displays used (1-4). $S$ = stationary white field, $W / X=a$ white field that alternated with a white " $X$ " at 1-sec intervals, $F=$ flickering white light $(.5 \mathrm{sec}$ on, .5 sec off), $M=$ moving white light (see text).
Table 1

Trial of First Keypeck Occurrence

\begin{tabular}{crrrrr}
\hline & \multicolumn{5}{c}{ Autoshaping Condition } \\
\cline { 2 - 6 } Bird & 1 & 2 & 3 & 4 & 1 \\
\hline 1 & 63 & 9 & 2 & 5 & 4 \\
2 & 109 & 2 & 1 & 7 & 2 \\
3 & 14 & 1 & 2 & 4 & 1 \\
4 & 133 & 1 & 3 & 2 & 1 \\
5 & 2 & 1 & 1 & 3 & 1 \\
6 & 24 & 2 & 6 & 7 & 1 \\
7 & 10 & 1 & 3 & 1 & 1 \\
8 & 32 & 3 & 1 & 3 & 1 \\
9 & 53 & 2 & 4 & 1 & 1 \\
\hline
\end{tabular}

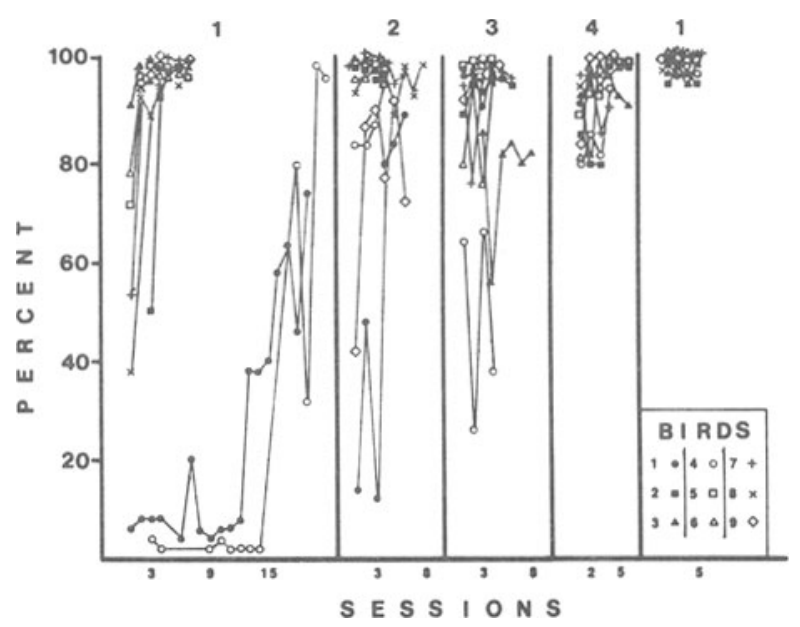

Figure 2. Percent of the trials during which a keypeck occurred. The number above each panel denotes the AS array in effect.

mean number of trials (group data) presented before a keypeck emerged was 49 . The table indicates that our birds yielded data comparable to those published by Brown and Jenkins (1968). The table indicates that AS2, AS3, and particularly AS4 maintained responding. Most of the birds responded within the first two trials of each session once pecking was established. Introduction of novel CS arrays yielded slight increases in the number of trials that occurred before subjects responded. No keypecks occurred during the ITIs.

Figure 2 shows the percent of the trials during which a keypeck occurred. With the exception of Birds 1 and 4, each bird approached $100 \%$ within two sessions. Each time a new CS array was introduced (AS2, AS3, and AS4), several birds showed an initial decrease in responses. The second time AS1 was introduced, no disruption was noted. Figure 3 displays the cumulative response distributions emitted by each bird during each AS condition. During the acquisition condition (AS1), each bird responded only to Keys 4,5 , and 6 . Birds 2 , 3,5 , and 8 responded predominantly to Key 4 , the stationary white CS. Birds 1 and 6 emitted the majority of their pecks to Key 5, the key alternating white and X. 


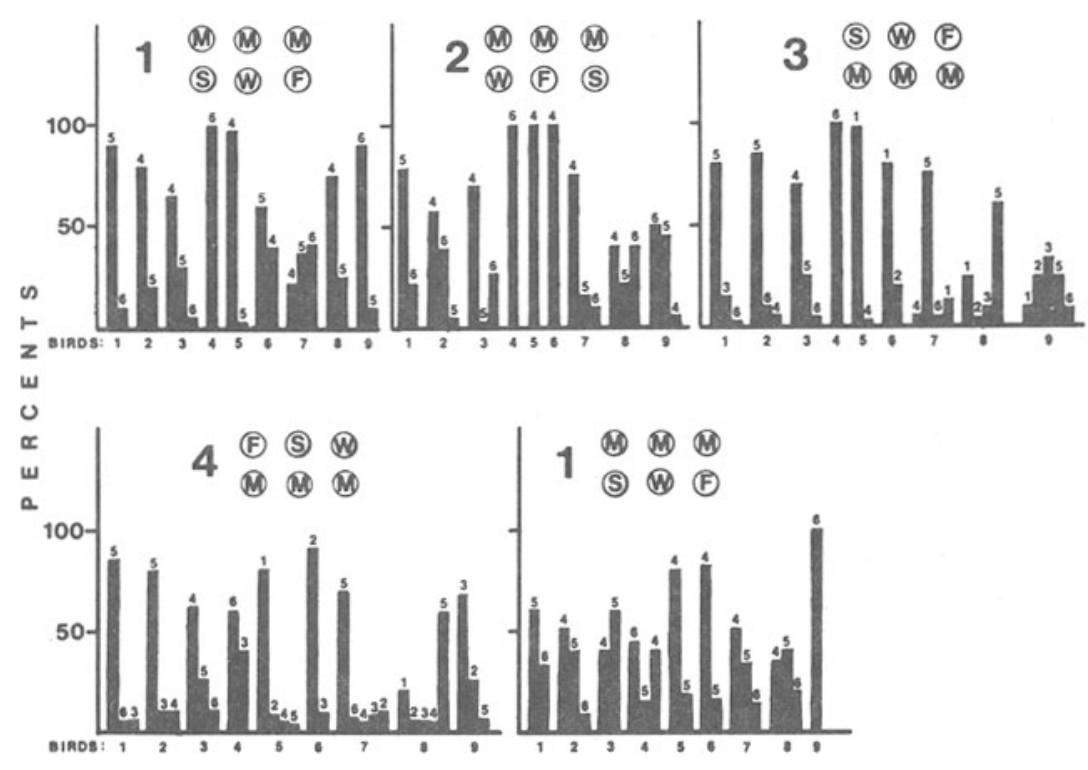

Figure 3. Cumulative response distributions emitted by each bird in each condition. The number above each bar represents the key the pecks were emitted on.

Birds 4 and 9 responded almost exclusively to Key 6 , flickering white.

During AS2, five of the birds $(1,3,4,5$, and 9) kept pecking the same keys they chose during AS1. Birds 6 and 7 shifted to Key 4, presumably to continue pecking the white/X alternation CS. Similarly, Birds 2 and 8 shifted to Keys 4 and 6, which presented the white/X alternation and stationary white CS, respectively.

When the AS3 condition was introduced, six birds $(1,2,3,4,7$, and 8$)$ continued to peck the same keys as before, although they now were presenting the moving CS. Birds 5 and 6 shifted to Key 1 (stationary CS), and Bird 9 shifted to Key 3 (flickering CS). The response distributions of AS4 are similar to those of AS3, except for Bird 6, who shifted to Key 2 (stationary CS). During the second exposure to AS1, each bird except Bird 6 produced response distributions similar to those emitted in the original AS1 condition.

\section{DISCUSSION}

In general, six of the birds $(1,2,3,4,7$, and 8$)$ appeared to be under the control of particular keys regardless of the CS associated with them. Birds 5 and 6 , however, showed evidence of being under the discriminative control of the stationary and white/X CSs. Bird 9, for the majority of the sessions, pecked the flickering white CS. The data lead us to suspect that, at least in the present study, autoshaped responding was maintained on a superstitious basis. Although there was an initial contributory classical conditioning component (i.e., the pairing of CSs with food regardless of behavior), each peck was directly reinforced. The data support Brown and Jenkins' (1968) analy sis that au toshaped behavior is a matter of a "species-specific predisposition," a high operant level for pecking that is superstitiously reinforced (Morse \& Skinner, 1957; Skinner, 1948). In the present case, pecking was directly reinforced, but the choice of key or CS was superstitious. Pisacreta (1982b) required pigeons to peck six to nine illuminated response keys, once each, in order to produce a reinforcer. Although no specific sequence of keypecking was required, each bird developed a particular key sequence that it emitted during the majority of the trials. In a related study, Pisacreta (1982a) trained birds to peck five keys. A peck to any key changed the stimulus on the key. Reinforcement was available when all the keys showed the same stimulus. With up to 12 stimuli available, each bird produced particular matches $60 \%$ to $100 \%$ of the trials.

Our observations were similar to those reported by Wessells (1974), in that there appears to be a confounding of responsereinforcer and CS-US influences. Our birds also showed similar stereotyped prepecking behavior, which included (1) orienting toward the keys, (2) pacing in front of the keys, (3) alternately looking at the CSs and hopper hole, (4) pecking motions toward a particular key, and (5) the occurrence of a keypeck. Since most of our birds pecked particular keys regardless of the CS present, autoshaping was probably initially adventitiously or superstitiously established and then maintained by responseproduced reinforcers.

Rescorla (1967) demonstrated that it is the correlation between the CS and US rather than the association of the two that is crucial. Several researchers have posited a similar view of the two that is crucial. Several researchers have posited a similar view that autoshaping relies on the informativeness of the CS in relation to the US (Allaway, 1971; Gamzu \& Williams, 1973; Williams \& Williams, 1969). The present study provided several CSs that were informationally redundant and equally correlated with the US. The results suggest that superstitious behavior may be a contributing factor in autoshaping situations.

\section{REFERENCES}

Allaway, T. A. Attention, information and auto-shaping. Unpublished doctoral dissertation, University of Pennsylvania, 1971.

Bindra, D. A unified account of classical conditioning and operant training. In A. H. Black \& W. F. Prokasy (Eds.) Classical conditioning II: Current theory and research. Englewood Cliffs, N.J: Prentice-Hall, 1972.

Brown, P. L., \& Jenkins, H. M. Auto-shaping of the pigeon's 
key-peck. Journal of the Experimental Analysis of Behavior, $1968,11,1-8$.

Egaer, M. D., \& Miller, N. E. When is reward reinforcing? An experimental study of the information hypothesis. Journal of Comparative and Physiological Psychology, 1963, 56, 132 137.

Ferster, C. B., \& Skinner, B. F. Schedules of reinforcement. Englewood Cliffs, N.J: Prentice-Hall, 1957.

Fisher, M. A., \& Catania, A. C. Autoshaping: Relation of feeder color to choice of key color. Bulletin of the Psychonomic Society, 1977, 9, 439-442.

GAMZU, E. Associative and instrumental factors underlying the performance of a complex skeletal response. Unpublished doctoral dissertation, University of Pennsylvania, 1971.

Gamzu, E. R., \& Williams, D. R. Associative factors underlying the pigeon's keypecking in autoshaping procedures. Journal of the Experimental Analysis of Behavior, 1973, 19, 225-232.

Gonzalez, F. A. Effects of varying the percentage of key illuminations paired with food in a positive automaintenance procedure. Journal of the Experimental Analysis of Behavior, 1974, 22, 483-490.

HeArst, E., \& Jenkins, H. M. Sign tracking: The stimulusreinforcer relation and directed action. Austin, Tex: Psychonomic Society, 1974.

Morse, W. H., \& Skinner, B. F. A second type of superstition in the pigeon. American Journal of Psychology, 1957, 70, 308311.

Picker, M., \& Poling, A. Choice as a dependent measure in autoshaping: Sensitivity to frequency and duration of food presentation. Journal of the Experimental Analysis of Behavior, 1982, 37, 393-406.

Pisacreta, R. Preferences among stimulus matches in the pigeon.
Journal of the Experimental Analysis of Behavior, 1982, 38, 191-199. (a)

Pisacreta, R. Some factors that influence the acquisition of complex, stereotyped, response sequences in pigeons. Journal of the Experimental Analysis of Behavior, 1982, 37, 359-369. (b)

Rescorla, R. A. Pavlovian conditioning and its proper control procedures. Psychological Review, 1967, 74, 71-80.

Schwartz, B., \& Gamzu, E. Pavlovian control of operant behavior. In W. K. Honig \& J. E. R. Staddon (Eds.), Handbook of operant behavior. Englewood Cliffs, N.J: Prentice-Hall, 1977.

Schwartz, B., \& Williams, D. R. The role of the responsereinforcer contingency in negative auto-maintenance. Journal of the Experimental Analysis of Behavior, 1972, 71, 351-357.

Skinner, B. F. "Superstition"' in the pigeon. Journal of Experimental Psychology, 1948, 38, 168-172.

Wasserman, E. A. Auto-shaping: The selection and direction of behavior by predictive stimuli. Unpublished doctoral dissertation, University of Indiana, 1972.

Wasserman, E. A., \& Anderson, P. A. Differential autoshaping to common and distinctive elements of positive and negative discriminative stimuli. Journal of the Experimental Analysis of Behavior, 1974, 22, 491-496.

Wessells, M. G. The effects of reinforcement upon the prepecking behaviors of pigeons in the autoshaping experiment. Journal of the Experimental Analysis of Behavior, 1974, 21, 125-144.

Williams, D. R., \& Williams, H. Automaintenance in the pigeon: Sustained pecking despite contingent non-reinforcement. Journal of the Experimental Analysis of Behavior, 1969, 12, 511-520.

(Received for publication November 27, 1982.) 